\title{
Constituição das Regras e o Desenvolvimento Moral na Teoria de Piaget: Uma Reflexão Kantiana
}

\author{
Rules Constitution and the Moral Development in the Theory of Piaget: \\ A Kantian Reflection
}

\author{
Sávio Silveira de Queiroz*, Juliana Peterle Ronchi \& Rosana Suemi Tokumaru \\ Universidade Federal do Espírito Santo
}

\begin{abstract}
Resumo
Os jogos de regras possuem complexos sistemas de regras expressos em relações sócio-culturais, favorecendo, segundo Piaget, o estudo da autonomia versus heteronomia, uma das dimensões do desenvolvimento moral. Nosso objetivo foi analisar a importância da constituição das regras para Piaget, examinando apropriações que ele faz de termos kantianos, proporcionando uma reflexão sobre termos que têm sido empregados diferentemente dos seus significados filosóficos originais. Observamos que a diferenciação entre duas morais, e a concepção de respeito, fundamental para o entendimento desta diferenciação, são pressupostos kantianos utilizados por Piaget. Concluímos que o entendimento do desenvolvimento moral na teoria piagetiana se evidencia quando precisamos alguns termos nos escritos kantianos.

Palavras-chave: Piaget; Kant; desenvolvimento moral; jogos de regra.

Abstract

The games of rules have complex systems of rules expressed in socio-cultural relations favoring, according to Piaget, the study of autonomy versus heteronomy - a dimension of the moral development. Our aim was to analyze the importance of the rules' constitution for Piaget, examining his appropriations of Kantian terms, providing a reflection on terms that have been differently used from their original philosophical meanings. We observed that the differentiation between the two moral systems and the conception of respect are Kantian presuppositions used by Piaget. We concluded that the understanding of the moral development in the Piagetian theory became evident when terms in the Kantian writings are specified.

Keywords: Piaget; Kant; moral development; games-of-rules.
\end{abstract}

A influência da obra de Imannuel Kant na Epistemologia Genética de Jean Piaget tem sido salientada por diferentes autores (Biaggio, 1999; Boto, 2001; Freitas, 2002; Ramozzi-Chiarottino, 1988, 1994).

De acordo com Freitas (1999, 2002), Ramozzi-Chiarottino (1988) e Wadsworth (1997) Piaget tinha como projeto construir uma teoria do conhecimento considerando os aspectos da moralidade. Para ele, ao estudar a evolução biológica do ser humano, seria impossível não descobrir também como se constitui a moral humana (Freitas, 2002).

Ramozzi-Chiarottino (1994), por exemplo, nos apresenta uma passagem escrita pelo próprio Piaget em um dos seus artigos autobiográficos, no qual ele mesmo caracteriza sua obra como um "kantismo evolutivo". Freitas (2002) também se refere a esse termo. Segundo Ramozzi-Chiarottino $(1988,1994)$ pode-se compreender a obra piagetiana como um retorno à tese kantiana que se esclarecerá graças à biologia e ao seu entendimento do Homem como um animal simbólico.

*Endereço para correspondência: Rua Constante Sodré, 1077, Apto. 803, Praia do Canto, Vitória, ES, Brasil, CEP 29055420.E-mail: savioqueiroz@terra.com.br
Ao construir uma teoria científica do desenvolvimento moral Piaget vê na compreensão dos jogos de regras um campo propício para estudar uma das dimensões do desenvolvimento moral: a heteronomia versus a autonomia, uma vez que mantém a tese de Kant de que há duas morais (Biaggio, 1999; Freitas, 2002). Para ambos os autores apenas a autonomia é efetivamente a lei moral, mas enquanto para Kant a heteronomia contraria o princípio da moralidade apresentando-se como uma falsa liberdade, pois a vontade não se dá por ela mesma (Kant, 1788/2002), Piaget levanta a hipótese de que a heteronomia é sucedida pela autonomia (Piaget, 1932/1994). Freitas (2002) justifica o termo "kantismo evolutivo" afirmando que, além de manter a tese kantiana das duas morais (autonomia e heteronomia) Piaget propõe que a primeira seja entendida como evolução da segunda. A escolha dos jogos de regras para esta investigação justifica-se, segundo Piaget (1932/1994), já que estes possuem complexos sistemas de regras e, além disso, são expressos em relações sócio-culturais.

Este artigo tem como objetivo analisar a importância da constituição das regras na teoria de Jean Piaget para o entendimento do desenvolvimento moral. Para cumprir este objetivo examinaremos as apropriações que esse autor faz 
de termos da filosofia de Imannuel Kant. Os termos analisados serão: regra em Piaget e proposições fundamentais da razão prática pura em Kant; constituição da autonomia em Piaget e juízo sintético a priori em Kant; autonomia e heteronomia em Piaget e autonomia e heteronomia em Kant; e, por fim, respeito em Piaget e respeito em Kant.

Kant estrutura sua obra em torno de duas grandes questões: a primeira tratava-se do alcance das esferas do conhecimento; e a segunda versava sobre "o problema moral", de como deve ser a ação humana para "alcançar o bem supremo" (Rohden \& Moosburger, 1980).

Assim, um estudo da obra piagetiana à luz da filosofia kantiana propicia o resgate da reflexão sobre termos que têm sido empregados com variadas interpretações dos seus significados filosóficos originais. Como bem salienta Ramozzi-Chiarottino (1988, p. 2):

. . . é importante notar que há muitos outros obstáculos a vencer para interpretar corretamente o pensamento de Piaget. Um deles é o vocabulário. Termos utilizados pelo pensador são costumeiramente entendidos à luz de prevalentes 'tradições' da Psicologia ou da Pedagogia ... sem lhes dar, no entanto, o significado exato que deveriam receber, no âmbito das noções piagetianas.

Esse estudo será baseado no livro de Piaget: " $O$ juízo moral na criança" (1932/1994), pois segundo Freitas (2002) esse livro se mostra como a primeira tentativa de examinar empiricamente sua problemática da moral e, ainda de acordo com Biaggio (1999), é nesse livro que Piaget identifica as condutas das crianças em relação às regras.

Para a compreensão a que se propõe o trabalho utilizaremos como obra principal de Kant a "Crítica da razão prática" (1788/2002), pois nessa obra Kant faz a preleção da autonomia, da heteronomia e do dever moral (Reale \& Antiseri, 1990).

Portanto, o nosso trabalho consistirá em apresentar a importância da construção das regras para o desenvolvimento moral segundo Piaget, criticando os termos utilizados por ele com base na obra "Crítica da razão prática" de Kant (1788/2002), possibilitando, desta forma, uma aproximação entre as obras de Piaget e Kant e uma interpretação da teoria piagetiana à luz da filosofia kantiana.

\section{A Constituição da Regra em Piaget}

Já nas primeiras páginas de seu livro "O juízo moral na criança", Piaget nos adverte sobre o sentido e o objetivo de sua obra: "Propusemo-nos a estudar o juízo moral, e não os comportamentos ou os sentimentos morais" (Piaget, 1932/1994, p. 21) e que, para o estudo do juízo moral, utilizar-se-ia de análises das "regras do jogo social", na medida em que "toda moral consiste num sistema de regras, e a essência de toda moralidade deve ser procurada no respeito que o indivíduo adquire por essas regras" (Piaget, 1932/1994, p. 23).

Piaget salienta que geralmente as regras morais que a criança aprende a respeitar já chegam até ela elaboradas pelos adultos, principalmente pelos pais, ou seja, já che- gam como verdades. No estudo a que ele se propõe examinar, as regras do jogo de bolinhas de gude, as crianças maiores transmitem as regras para as crianças menores; logo, as leis são passadas de criança para criança. As crianças maiores, por sua vez, já podem escolher se modificam ou não as regras do jogo. Desse modo pode-se examinar de que forma se pratica a regra: se ela é algo sagrado (heterônoma) ou algo sobre o que se pode decidir obedecer ou não (autônoma). Piaget conduz suas observações no sentido de esclarecer de que forma os indivíduos se ajustam às regras, quais entendimentos têm da regra de acordo com sua idade e seu desenvolvimento mental e como adquirem consciência e domínio da regra (Piaget, 1932/ 1994).

Piaget entrevistou aproximadamente vinte crianças de quatro a treze anos e identificou de acordo com a prática das regras quatro estágios: (a) no primeiro estágio (0-2 anos), assinalado como estágio motor, as crianças não fazem uso de regras, há simplesmente uma manipulação motora e individual das bolinhas, não há atividade social, as bolinhas exploradas parecem servir mais a um conhecimento físico do objeto; (b) no segundo estágio (2-5 anos) chamado por Piaget de egocêntrico, as crianças recebem do exterior regras codificadas e jogam imitando o exemplo, mas não há um interesse em encontrar parceiros para jogar ou ganhar o jogo, pois as regras são utilizadas individualmente, cada criança joga para si, mesmo quando em grupo; (c) no terceiro estágio (7-8 anos) caracterizado por Piaget como o estágio da cooperação surge a importância de se ganhar o jogo; logo, há necessidade da sistematização das regras, ainda que em uma mesma partida observe-se variações referentes as regras gerais do jogo; (d) no quarto estágio (11-12 anos) as regras do jogo são definidas e entendidas minuciosamente por todos os jogadores. Piaget caracteriza esse estágio como da codificação das regras, pois agora as regras fazem parte da sociedade (Piaget, 1932/ 1994; Wadsworth, 1997).

No que concerne à consciência das regras Piaget divide-a em três estágios: o primeiro compreende o estágio motor e a metade do segundo estágio, descritos anteriormente, visto que “. . . a regra ainda não é coercitiva . . ." (Piaget, 1932/1994, p. 34); o segundo se inicia na segunda metade do estágio egocêntrico e termina na metade do estágio de cooperação, em que a regra é entendida como sagrada, “. . . de origem adulta e de essência eterna; toda modificação proposta é considerada pela criança como uma transgressão" (Piaget, 1932/1994, p. 34); e no terceiro, iniciado na segunda metade do terceiro estágio (da prática das regras), “. . . a regra é considerada como uma lei imposta pelo consentimento mútuo, cujo respeito é obrigatório, se se deseja ser leal, permitindo-se, todavia, transformá-la à vontade, desde que haja o consenso geral" (Piaget, 1932/1994, p. 34).

Assim, podemos observar o processo de interiorização das regras que no início mostram-se como exteriores ao sujeito, sagradas, e paulatinamente ganham entendimento e expressão livre, desde que um consenso social se estabeleça. 
Queiroz, S. S., Ronchi, J. P. \& Tokumaru, R. S. (2009). Constituição das Regras e o Desenvolvimento Moral na Teoria de Piaget: Uma reflexão Kantiana.

Piaget (1932/1994) antes de oferecer resultados ao leitor certifica-se de que as regras do jogo de bolinhas de gude são do mesmo tipo que as regras coletivas; ressalta que as regras as quais se refere, se constituem independentemente do sujeito, se transmitem de geração em geração e que para acontecer modificações nas regras, essas modificações têm que ser aprovadas pela coletividade. É interessante assinalar ainda que no estágio motor, embora não se observem regras, vê-se uma regularidade no comportamento dos sujeitos, de modo que as bolinhas ganham um caráter simbólico de acordo com suas brincadeiras, Piaget (1932/1994) salienta que essa regularidade e esse simbolismo observados apresentam-se como uma estrutura necessária para o desenvolvimento das regras. O que difere a regularidade da regra é o caráter obrigatório da segunda, em que prevalece o respeito seja ele unilateral ou mútuo.

\section{Proposições Fundamentais da Razão Prática Pura: Regras Práticas}

Para as aproximações entre Kant e Piaget, a que se propõe esse estudo, verifiquemos em Kant o termo regra.

Primeiramente Kant nos chama a atenção para o caráter de sua obra, segundo ele, o Juízo Moral é guiado e deve ser analisado pela vontade e sua causalidade, pois são as proposições fundamentais da razão em relação à vontade e à causalidade, que poderão ser aplicadas aos objetos e aos sujeitos com seus sentimentos, é a vontade que legisla sobre uma regra prática, Kant ainda afirma que “. . . a vontade livre tem que ser independente de condições empíricas (isto é, pertencentes ao mundo sensorial) e, contudo, determinável, assim uma vontade livre tem que encontrar, independentemente da matéria da lei, um fundamento determinante na lei" (Kant, 1788/2002, p. 49). Assim como Kant, para Piaget a vontade é a reguladora dos valores morais, pois, um ato de vontade ocorre quando um acontecimento é subordinado a uma escala de valores (Piaget, 1954/2001). Dessa forma, tanto Kant como Piaget pretendem estudar o Juízo Moral visto ser legislado pela vontade, sendo que os comportamentos ou sentimentos são apenas manifestações do Juízo Moral.

De acordo com Kant as "proposições fundamentais práticas são proposições que contêm uma determinação universal da vontade, determinação que tem sob si diversas regras práticas" (Kant, 1788/2002, p. 31-32, grifo do autor). A regra prática, segundo o autor, é fruto da razão e enquanto ação é meio para um determinado fim. As proposições fundamentais (regras práticas) podem ser máximas - hipóteses consideradas pelo sujeito que se mostram adequadas apenas para sua própria vontade - ou imperativos - em que uma ação como meio para um fim, acontece sempre sob o aspecto de uma regra válida para todos os sujeitos. Os imperativos podem ser de dois tipos: (a) "imperativos hipotéticos" em que a necessidade da ação é completamente determinada pela vontade, ou seja, só há regra se de fato o sujeito quiser alcançar aquele fim - por exemplo, "se quiseres juntar dinheiro, deves economizar"
(Kant, 1788/2002; Reale \& Antiseri, 1990); (b) "imperativos categóricos" são leis práticas ". . . que determinam a vontade enquanto vontade ..." (Kant, 1788/2002, p. 34), é o simples querer que deve ser determinado. Explica Kant: ... a regra só é objetiva e universalmente válida se vale independentemente de condições subjetivas e contingentes, que distinguem um ente racional de outro ... o simples querer é que deve ser determinado de modo completamente $a$ priori por aquela regra. Agora, se se considera que esta regra seja praticamente correta, então ela é uma lei, porque ela é um imperativo categórico. Portanto leis práticas referem-se unicamente à vontade, sem consideração do que é realizado através da causalidade da mesma, e pode-se abstrair desta última (enquanto pertencente ao mundo sensorial) para as ter como puras. (Kant, 1788/2002, p. 35).

Piaget ao fazer sua investigação sobre o juízo moral busca compreender como se dá o respeito dos indivíduos pelas regras. Analisamos que sua investigação é feita tendo por base as proposições fundamentais da razão prática pura de Kant (1788/2002), pois Piaget pretende observar como os sujeitos lidam com as regras de acordo com cada idade e que tipo de obrigação às regras os incitam, se proposições subjetivas (máximas) ou leis práticas (imperativos) (Kant, 1788/2002).

Quando Piaget nos fala do estágio três das práticas das regras, o qual ele chama de estágio de cooperação, podemos fazer um paralelo com as máximas kantianas (proposições subjetivas), pois a criança embora já tenha um interesse em ganhar o jogo, ainda não apresenta uma sistematização das regras utilizadas para tal fim. $O$ interesse da criança nesse estágio é lutar com seus parceiros para ganhar, sem, contudo, entender as minúcias das regras do jogo, segundo Piaget (1932/1994). Poderiam essas crianças, dessa forma, estabelecer máximas para continuar jogando com seus colegas e alcançar a vitória? Segundo os exemplos encontrados em "O juízo moral na criança" as crianças do terceiro estágio das práticas das regras cometem desvios consideráveis durante o jogo com os experimentadores, acerca da informação das regras. Embora Piaget ressalte que é nesse estágio que o jogo começa a ser de fato social, a cooperação ainda está muito limitada sob o ponto de vista da jurisprudência. As crianças dessa idade, ainda não são capazes de legislar sobre um conjunto de regras, cada um ainda persiste com uma opinião pessoal sobre as regras do jogo. Piaget fala de uma "moral provisória" (Piaget, 1932/1994, p. 47), pois é apenas no quarto estágio (da prática das regras) que se tem uma compilação de leis a serem seguidas que podem ser discutidas e modificadas desde que haja um consenso.

Kant ao nos trazer a lei fundamental da razão prática pura: "age de tal modo que a máxima de tua vontade possa sempre valer ao mesmo tempo como princípio de uma legislação universal" (Kant, 1788/2002, p. 51), mostra a importância da universalidade que é a forma da lei moral, ou seja, embora as crianças do estágio de cooperação façam uso da regra, o importante para essa questão é saber se essa regra pode ser aplicada a todos em todas as situa- 
ções. Segundo Reale e Antiseri (1990) "portanto, a moralidade não consiste naquilo que se faz, mas no como se faz aquilo que se faz" (p. 907).

Do exposto acima concluímos que apenas no quarto estágio da prática das regras é que se pode falar em uma moral enquanto autonomia da vontade (Kant, 1788/2002), pois é só nesse estágio descrito por Piaget que se encontra "interesse pela regra em si mesma" (Piaget, 1932/1994, p. 50).

\section{Juízo Sintético A Priori: a Relação Sujeito x Objeto}

Segundo Ramozzi-Chiarottino (1988) a teoria piagetiana se fundamenta na ação do sujeito sobre seu meio, logo o conhecer só pode se dar quando o sujeito manipula o objeto, quando entra em contato com ele.

Para Kant o verdadeiro conhecimento consiste em proposições ou juízos necessários e universais. Se "um juízo consiste na conexão de dois conceitos, dos quais um (A) cumpre a função de sujeito e outro (B) cumpre a função de predicado" (Reale \& Antiseri, 1990, p. 867), temos então que, se o predicado estiver contido dentro do sujeito, esse juízo será "analítico" e, se o predicado estiver acrescentando ao sujeito algo que não lhe é próprio, o juízo será "sintético". O "juízo analítico" não nos traz a necessidade de recorrer à experiência, ele é a priori, portanto necessário e universal, mas não amplificador do conhecimento. Enquanto o "juízo sintético" ao nos trazer algo sobre o objeto que não está contido claramente nele é amplificador do saber, no entanto, por ser a posteriori não é universal e necessário e nos faz recorrer à experiência não sendo pressuposto de saber científico. Assim, a ciência não se baseia em juízos analíticos ou sintéticos. A ciência baseia-se em juízos que guardam o a priori (a necessidade e a universalidade) e a fecundidade da síntese. São eles os "juízos sintéticos a priori" (Reale \& Antiseri, 1990).

Essa explicação sobre juízos em Kant se faz necessária, pois podemos verificar que Piaget nas suas observações e conclusões sobre a construção da concepção da regra na criança utiliza-se do fundamento do "juízo sintético a priori”. O fundamento deste juízo é que a razão deve procurar na natureza aquilo que a própria natureza permite como possibilidade de conhecimento. Kant considera que não é o sujeito que, conhecendo, descobre as leis, mas ao contrário, que é o objeto, quando é conhecido, que se adapta às leis do sujeito que o recebe de modo cognitivo (Reale \& Antiseri, 1990). Concluímos que, para Piaget, isso é determinante para o real entendimento das regras pela criança e para a constituição da autonomia, pois, segundo ele, é à medida que a criança lida com a regra no seu meio ambiente que a noção verdadeira da regra se constrói. Assim, no encontro verdadeiro do sujeito com as práticas das regras, pelas interações cooperativas, se constitui a concepção da regra não estabelecida como algo sagrado e pronto, mas como algo que se pode mudar e inovar desde que haja reciprocidade e respeito mútuo entre os sujeitos que interagem, condição sine qua non ao surgimento da autonomia (Piaget, 1932/1994).

\section{As Duas Morais: Autonomia e Heteronomia em Piaget e Kant}

Piaget (1932/1994) nos revela a existência de três tipos de regras de acordo com as condutas das crianças, em relação às práticas das regras e à consciência das regras: (a) a regra motora; (b) a regra coercitiva; e (c) a regra racional. Embora Piaget nos fale em estágios da prática das regras e estágios da consciência das regras, salienta que na realidade esses aspectos se mostram sem interrupções, numa continuidade que, na maioria das vezes, não se mostra linear. Ele mesmo afirma:

... o aparecimento de um novo tipo de regra no plano da prática nem conduz mais ao aparecimento de uma nova consciência da regra, devendo cada operação psicológica ser retomada nos diferentes planos da ação e do pensamento. (Piaget, 1932/1994, p. 75).

Temos então que, a princípio, as crianças assimilam as regras num meio em que são impostas pelos adultos, há um respeito unilateral às regras; pela coação externa é que são obedecidas, revestidas de caráter sagrado e mítico. À medida que o respeito unilateral dá lugar ao respeito mútuo entre os sujeitos, a criança toma consciência da regra e, com a cooperação, a criança entende a razão de ser delas.

Kant salienta que apenas a autonomia é a lei moral efetiva, enquanto a heteronomia é falsa expressão da lei moral. No entanto, para atender aos nossos propósitos neste trabalho, consideramos a afirmação de Freitas (2002) pela qual "os resultados de suas pesquisas [de Piaget] sobre as regras do jogo levam-no a sustentar a tese kantiana da existência de duas morais: a moral da heteronomia e a moral da autonomia" (p. 305). Pois, entendemos que Kant, ao salientar que a heteronomia é falsa expressão da lei moral, não nos mostra que ela inexiste como uma moral, apenas salienta que ela não tem como princípio o imperativo categórico. Assim, Piaget ao discutir o respeito às regras tendo por base a tese kantiana das duas morais, demonstra-nos a possibilidade de existência de duas morais: (a) uma moral da heteronomia, moral provisória; e (b) uma moral da autonomia, a efetiva lei moral, ligadas respectivamente à coação e à cooperação (Freitas, 2002; Piaget, 1932/1994).

Kant em "Crítica da razão prática" salienta que a lei moral é uma lei da causalidade, causalidade que segundo ele refere-se à conexão dos objetos, enquanto fenômenos, a uma experiência na qual a razão é determinante da vontade. "Só então, a razão, na medida em que determina por si mesma a vontade (não está a serviço das inclinações) é uma verdadeira faculdade de apetição superior ..." (Kant, $1788 / 2002$, p. 42) e a vontade como "independente de condições empíricas, por conseguinte como vontade pura ..." (Kant, 1788/2002, p. 52), cria um vínculo de obrigação com a lei moral. Dessa forma, para Kant a autonomia é autonomia da vontade enquanto

... único princípio de todas as leis morais e dos deveres conformes a elas: contrariamente, toda a heteronomia do arbítrio não só não funda obrigação alguma, mas, 
antes, contraria o princípio da mesma e da moralidade da vontade. (Kant, 1788/2002, p. 55).

Observamos que em Piaget (1932/1994) a heteronomia se liga ao egocentrismo, pela qual a criança considera as ordens como deveres e valores absolutos aos quais está obrigada. Como diria Kant (1788/2002) a vontade está submetida, sendo considerado como "algo bom" todo ato de obediência irrestrita às ordens recebidas pelos adultos. $\mathrm{Na}$ autonomia há uma prática racional das regras como bem salienta Piaget (1932/1994) - a regra passa a ser expressão livre da consciência; a vontade é que determinará a ação.

Kant ao nos falar sobre a arbitrariedade de uma máxima que leva a uma heteronomia do arbítrio enfatiza que a lei moral verdadeira se dá única e exclusivamente pela autonomia e afirma:

. . . a máxima, porém, que desse modo jamais pode conter a forma universal-legislativa, não só não institui desse modo nenhuma obrigação mas contraria ela mesma o princípio de uma razão prática pura e com isso, portanto, também a disposição moral, ainda que a ação que deriva dela devesse ser conforme à lei. (Kant, $1788 / 2002$, p. 56).

Observamos então que, a máxima kantiana e a heteronomia em Piaget (1932/1994) proporcionam uma falsa liberdade, pois em ambas a vontade está condicionada a algo, e somente quando a vontade é determinante da própria vontade, constituindo-se como imperativo categórico, a lei moral se expressa como "autonomia da razão prática pura" (Kant, 1788/2002).

Piaget, ao propor de modo experimental um problema de psicologia moral, verifica as proposições de Kant em seus estudos e, ratificando a tese kantiana das duas morais (autonomia e heteronomia), afirma que: “. . . é a partir do momento em que a regra de cooperação sucede à regra de coação que ela se torna uma lei moral efetiva" (Piaget, 1932/ 1994, p. 64). Piaget não só confirma Kant como também nos mostra empiricamente que a autonomia sucede a heteronomia, mediante o contato das crianças com as regras (Piaget, 1932/1994), e que essa sucessão é importante no desenvolvimento da criança na medida em que só há lei moral enquanto vontade pura do ser, enquanto imperativo categórico.

Um outro fato que pode comprovar a relação das morais da autonomia e heteronomia em Piaget (1932/1994) e Kant (1788/2002) mostra-se quando o primeiro nos relata em seus estudos sobre justiça ${ }^{1}$ que “. . . o desenvolvimento da justiça supõe a autonomia" (Piaget, 1932/1994, p. 239) e que a reciprocidade, diretamente proporcional à autonomia, sendo a priori é o ". . . equilíbrio ideal ...." (Piaget, 1932/1994, p. 238) para o qual tende um fato. Dessa forma Piaget (1932/1994) ressalta: "em conclusão, encontramos assim, no campo da justiça como nos campos anteriores, a oposição de duas morais sobre a qual insistimos tão freqüientemente" (Piaget, 1932/1994, p. 243).

${ }^{1}$ Justiça para ambos significa punibilidade da transgressão de uma lei moral (Piaget, 1932/1977, 1932/1994; Kant 1788/ 2002).
É interessante ressaltar também que o significado de a priori é fundamental na obra kantiana (Caygill, 2000), como bem salientamos ao explicitar o conceito de "juízos sintéticos a priori" e isso não se mostra diferente na teoria piagetiana, visto que “. . . entendemos por a priori não naturalmente uma idéia inata, mas uma norma para a qual a razão tem que tender, conforme vai se depurando" (Piaget, 1932/1994, p. 238).

Embora tenhamos salientado a relação do significado de justiça em Kant e Piaget, o fizemos para clarificar a noção de heteronomia e autonomia em ambos. No entanto, não vamos nos aprofundar no assunto visto ser o nosso objetivo falar da constituição da noção de regras em Piaget e suas apropriações filosóficas de termos kantianos para o desenvolvimento dessa concepção.

O que se torna importante destacar é que, como Kant, Piaget aponta que a razão prática pura somente se prova em nós pela autonomia (Kant, 1788/2002; Piaget, 1932/ 1994):

Mas é certo que o equilíbrio moral, constituído pelas noções complementares do dever heterônomo e da sanção propriamente dita, é um equilíbrio instável, pelo fato de que a personalidade não encontra nele seu desenvolvimento completo. À medida que a criança cresce, a submissão de sua consciência à consciência adulta parece-lhe menos legítima, e, salvo os casos de desvios morais propriamente ditos, que são constituídos pela submissão interior definitiva (os adultos que continuam crianças toda sua vida) ou pela revolta duradoura, o respeito unilateral tende, por si mesmo, ao respeito mútuo e à relação de cooperação, a qual constitui o equilíbrio normal (Piaget, 1932/1977, p. 129).

\section{A Importância do Respeito para o Desenvolvimento Moral}

Vimos até aqui que tanto em Kant como em Piaget a autonomia é o princípio da lei moral efetiva e, ainda, como se dá sua constituição segundo Piaget (1932/1994). Vejamos agora como o respeito às regras é importante para o desenvolvimento moral e, qual a sua relação com a heteronomia e a autonomia.

Segundo Piaget (1932/1994) a cooperação e o respeito mútuo são aspectos sem os quais não há constituição da autonomia. Para o autor, ainda, o respeito mútuo só é verdadeiro enquanto respeito mútuo de duas "personalidades", visto que a personalidade é a própria consciência moral. De acordo com Piaget (1932/1994, 1954/2001) a personalidade se constitui na vida social, é algo externo. Assim, e isso é fundamental para a compreensão da importância do respeito no desenvolvimento moral, há uma grande diferença entre consentimento mútuo e respeito mútuo. O primeiro, segundo Piaget (1932/1994), basta para justificar o motivo da construção das regras do jogo. No entanto, quando se fala em regras morais, há que se falar em respeito mútuo, pois o respeito se mostra como “... admiração por uma personalidade, enquanto, justamente essa personalidade se submete a regras" (Piaget, 1932/1994, p. 84). 
Como nos mostra Freitas (2002) o livro "O juízo moral na criança" pode ser compreendido ". . . como um estudo psicogenético sobre as relações entre o respeito e a lei moral” (p. 304), uma vez que Piaget “. . . atenta para o fato de que havia um acordo entre autores de diferentes orientações teóricas quanto ao fato de que o respeito é o sentimento fundamental da vida moral" (p. 304).

Para Kant (1788/2002) o respeito nunca estará relacionado aos objetos, mas somente às pessoas, pois se trata de um reconhecimento à moralidade do outro que se apresenta a mim. O sentimento moral que o respeito pela lei moral incita, inspira o dever, em que a ação é determinada pela vontade. Destarte, Kant (1788/2002) nos fala de duas maneiras de relação com a lei moral, uma de dever e uma de obrigação, nesta age-se de acordo com o dever (heteronomia - falsa liberdade), naquela age-se pelo dever (autonomia moral efetiva).

Devemos aqui salientar a relação que faz Piaget (1932/ 1994) entre: a autonomia e respeito mútuo; e a heteronomia e o respeito unilateral. Quando há respeito unilateral a ação acontece em conformidade ao dever, ou seja, acontece como obrigação. A criança procede da forma como foi ordenada, geralmente pelo adulto; a regra se apresenta como algo pronto e que chega até ela como sagrada. Por outro lado, quando há respeito mútuo, a ação é pelo dever, ocorre pela vontade como determinante da ação (Piaget, 1932/1994). Logo, no primeiro caso há legalidade e somente no segundo caso é que há moralidade, conforme salienta Kant (1788/ 2002). Desse modo, só existe lei moral efetiva quando não há obrigação e quando a determinação da ação da criança acontece mediante o respeito que ela apresenta pela lei e pelo dever moral, ou seja, quando a própria criança é o sujeito da lei moral.

Piaget (1932/1994) nos mostra claramente que sempre que uma prática for exterior à criança não haverá consciência autônoma. Só quando a criança pode legislar sobre as regras de acordo com sua própria vontade é que ela se conscientiza da razão de ser das regras. O respeito mútuo leva a criança à prática da cooperação, por reciprocidade nas relações com outras crianças, condição que efetiva a consciência da lei moral.

De fato, podemos perceber como o respeito, tratado por Piaget em um sentido kantiano, é fundamental para a constituição da realidade moral, pois, como dito anteriormente, o respeito mútuo sucede o respeito unilateral e sem aquele não há desenvolvimento da autonomia moral efetiva para Piaget (1932/1994).

\section{Considerações Finais}

Piaget tinha como objetivo, além de construir uma teoria do conhecimento, construir uma teoria do desenvolvimento moral (Freitas, 1999, 2002). Dessa maneira, salienta a importância da constituição das regras para o desenvolvimento moral na criança afirmando que a moral se organiza em um sistema de regras. Para ele, as regras se constituem na criança a princípio pela coação social e, na medida em que a criança é capaz de lidar com a regra em cooperação mútua com outras pessoas é que, de fato, entende a razão de ser das regras, alcançando autonomia moral.

Kant (1788/2002) afirma que a heteronomia é uma falsa moral; Piaget (1932/1994) salienta a importância da heteronomia para a constituição da autonomia. Como explicitamos anteriormente, o desenvolvimento de moral autônoma efetiva ocorre apenas quando a criança consegue legislar verdadeiramente sobre as regras. Logo, obedecer à regra que provém de outro, dá a criança a possibilidade de se questionar sobre a necessidade da aplicação da regra.

Quando Piaget caracteriza sua obra como um "kantismo evolutivo" (Freitas 2002; Ramozzi-Chiarottino, 1988, 1994) está afirmando que tem como base filosófica de sua investigação a teoria de Kant, e que, tem a intenção de verificar, ao perguntar ao sujeito que pratica a ação, como se dá o desenvolvimento moral, pois acredita que a autonomia é uma evolução da heteronomia (Freitas, 2002; Piaget, 1932/ 1994). Como indicam os resultados apresentados por Freitas (2002) não só a teoria do conhecimento de Piaget, mas também sua teoria da moral pode ser entendida como um "kantismo evolutivo". Piaget evidencia em seu estudo que o respeito unilateral dá lugar, paulatinamente, ao respeito mútuo, iniciando-se a constituição da consciência autônoma das leis (Freitas, 2002).

Dessa forma, o entendimento da teoria do desenvolvimento moral de Piaget se evidencia quando precisamos alguns de seus termos nos escritos de Kant. Por exemplo, a concepção de respeito, fundamental para o entendimento da diferenciação entre duas morais (autonomia e heteronomia), bem como a própria diferenciação da moral em duas. Quando ainda verificamos que as regras para Piaget só podem ser de fato compreendidas como tais se forem universais e necessárias, vemos aí o uso do pressuposto das proposições fundamentais da razão prática pura de Kant. Por exemplo, quando Piaget (1932/1994) nos mostra que as crianças de 7 a 9 anos começam a estabelecer leis que não podem ser tomadas ainda como prática racional das regras, a compreensão se esclarece por meio das máximas kantianas. Kant (1788/2002) afirma que as máximas são proposições fundamentais (regras práticas) que, no entanto, não se constituem como regras verdadeiras, pois não partem da vontade pura e não se aplicam a todas as pessoas em todas as situações. Desse modo, não são necessárias e tampouco universais.

Portanto, um estudo da teoria do desenvolvimento moral de Piaget, mais precisamente sobre a constituição das regras nas crianças, embasado à luz da teoria de Kant, não apenas proporciona melhor compreensão de alguns termos empregados por Piaget, mas também permite resgatar uma reflexão sobre termos aplicados em teorias psicológicas que têm sido utilizados com interpretações diversas de seus significados filosóficos originais. 


\section{Referências}

Biaggio, A. M. B. (1999). Universalismo versus relativismo no julgamento moral. Psicologia: Reflexão e Crítica, 12(1), 520.

Boto, C. (2001). Ética e educação clássica: Virtude e felicidade no justo meio. Educação e Sociedade, 22(76), 121-146.

Caygill, H. (2000). Dicionário Kant (A. Cabral, Trad.). Rio de Janeiro, RJ: Jorge Zahar.

Freitas, L. B. L. (1999). Do mundo amoral à possibilidade de ação moral. Psicologia: Reflexão e Crítica, 12(2), 447-458.

Freitas, L. B. L. (2002). Piaget e a consciência moral: Um kantismo evolutivo? Psicologia: Reflexão e Crítica, 15(2), 303308.

Kant, I. (2002). Crítica da razão prática (V. Rohden, Trad.). São Paulo, SP: Martins Fontes. (Original publicado em 1788)

Piaget, J. (1977). O juízo moral na criança. Rio de Janeiro, RJ: Zahar. (Original publicado em 1932)

Piaget, J. (1994). O juízo moral na criança (E. Lenardon, Trad.). São Paulo, SP: Summus. (Original publicado em 1932)

Piaget, J. (2001). Inteligencia y afectividad. Buenos Aires, Argentina: Aique. (Original publicado em 1954)

Ramozzi-Chiarottino, Z. (1988). Psicologia e epistemologia genética de Jean Piaget. São Paulo, SP: EPU.

Ramozzi-Chiarottino, Z. (1994). Em busca do sentido da obra de Jean Piaget. São Paulo, SP: Ática.

Reale, G., \& Antiseri, D. (1990). História da filosofia: Do humanismo a Kant. São Paulo, SP: Paulus.

Rohden, V., \& Moosburger, U. B. (1980). Kant I: Os Pensadores. São Paulo, SP: Abril Cultural.

Wadsworth, B. J. (1997). Inteligência e afetividade da criança na teoria de Piaget. São Paulo, SP: Pioneira. 